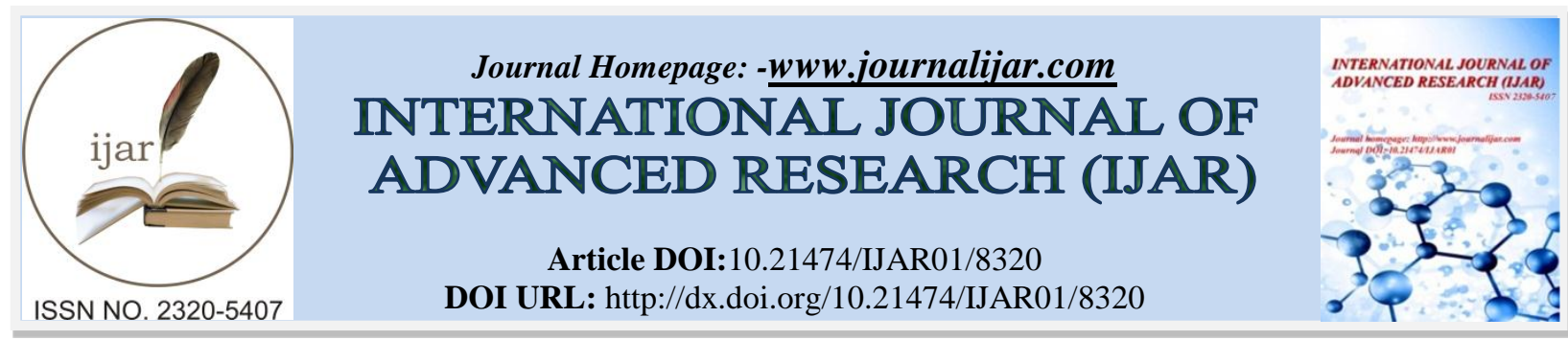

RESEARCH ARTICLE

\title{
AWARENESS OF PHYSIOTHERAPY AS A COURSE AND ITS IMPORTANCE IN HEALTH CARE AMONG HIGH SCHOOL STUDENTS- A CROSS SECTIONAL STUDY.
}

Priyadarshini Mishra ${ }^{1}$ and BSL Vidhyadhari ${ }^{2}$.

1. Institute of Health Sciences, Chandaka road ,Bhubaneswar, Odisha.

2. NIMS, college of physiotherapy OCHC Complex, Kharvel Nagar, Bhubaneswar, Odisha.

\section{Manuscript Info}

Manuscript History

Received: 04 November 2018

Final Accepted: 06 December 2018

Published: January 2019

Key words:-

Awareness, Profession, Physical Therapy, Government, Private, Intermediate, Pre-medical.

\section{Abstract}

Purpose:-The purpose of the study is to imbibe awareness of physiotherapy as a subject of choice similar to other medical fraternity and its importance in health care among high school students.

Objective:-This study is to promote awareness of physiotherapy as a subject of choice similar to other medical fraternity and its importance in health care among high school students.

Methods:-It is a crossectional study design with a sample size of 1000 high school students

Results:-In the survey done about the awareness of physiotherapy as a course it is very abashing to recognize that many of the students are unaware of physiotherapy its treatment methods, infrastructure ,it contains and their usage and role of physiotherapy as eminent part of treatment in variety of cases, thereby their ignorance in choosing physiotherapy as a subject .

Discussion:-The result of the present study seems to draw our attention to the fact that still many high school students are unaware of physiotherapy as a course to pursue.

Copy Right, IJAR, 2017,. All rights reserved.

\section{Introduction:-}

A profession is a rewarded occupation, especially one that involves prolonged training and a formal qualification whereas, a professional is engaged in a specified activity as main paid occupation rather than as an amateur. Health professionals play a central and critical role in improving access and quality health for the population. They asses, diagnose and treat various ailment with ease. This profession adds life to years not years to life creating a better life for ailing society.

Physical therapy, as a health care profession, was formally recognized in the second decade of the 20th century, after the World War I (1914-1918) whereas the profession was endorsed due to numerous emerging cases of poliomyelitis after World War II . World Confederation for Physical Therapy (WCPT) defines Physical Therapy as "A profession which is concerned with identifying and maximizing quality of life and movement potential within the spheres of promotion, prevention, intervention, and rehabilitation. This encompasses social, psychological, physical and emotional wellbeing.".The profession of Physical Therapy started off as a diploma program progressing to Bachelor and now leading to Master and PHD programs. It has grown such rapidly that the basic educational process required to become a PT is upgraded to the Doctor of Physical Therapy (DPT) degree. After DPT the need for further advancement in studies emerged realizing the need for equal credentials of old Bachelors in the market with 
the new graduates coming with the DPT degree. Hence, the Post Professional degree program was introduced. Similar concerned issues were raised when the mode was to move from Bachelor to the professional Master degree . The Post-Professional DPT degree permits PT to achieve degree uniformity with PT that holds the skilled DPT degree by filling in any gaps between their skilled baccalaureate academic degree education and current skilled DPT degree education.

American Physical Therapy Association (APTA) represents more than 80,000 Physiotherapist, Physiotherapist assistants, students and in U.S. Physical Therapy is ranked fifth in best healthcare jobs and eight in the 100 most excellent jobs in 2013. According to Vision 2020, the new graduates taking the national licensure examination in the field after 2020 will be required to hold at least DPT degree .Physiotherapist practice independently of other health care providers and also within interdisciplinary rehabilitation programs. Clinical specialization opportunities are also available, for Physiotherapist, in the fields of, Neurology, Orthopaedics, Geriatrics, Paediatrics, Women's Health, Sports and Clinical Electrophysiology . A study conducted by Prati and Liu. in October 2006 showed that the students have a positive attitude towards physical therapy. College students also observed the DPT as educating more competent practitioners. However, DPT programs should put in efforts to advocate their programs not only oncampus but also off-campus. DPT programs and APTA should promote more seriously to the public, the changes undergoing in the field of physical therapy .

Despite Physical Therapy being such a rapidly growing and emerging field there is not much work done to check the awareness of Physical Therapy and thus this study is being conducted as having the knowledge of awareness would help in creating more effective marketing strategies as many of these students could become practitioners as well as patients in future. Also understanding the factors for which the students do not choose Physical Therapy as their first option for career choices, would help in learning the misconceptions regarding theprofession that need to be corrected.

The objectives of the study are to determine the awareness and perception of Physical Therapy, to compare the frequency of physical therapy as career preference among students of government and private sector colleges and to identify the factors for which students do not choose Physical Therapy as first option for career choices

\section{Methodology:-}

1. Study design - Descriptive study

2. Study type - Cross-sectional study

3. Sample size -1000

4. Sampling method - convenient sampling

5. Settings - govt and private colleges, BBSR

6. Study duration -2 months

\section{Procedure:-}

A survey was conducted using questionnaire which was pretessted and modified with a convenient sample of two physiotherapist and 5 doctors of different fraternity. Then, the questionnaires, its content, wording, instructions and ease of completion were revised accordingly.

Questionnaire comprised three sections (part A,part B, partC) .Part A consists of subjective information ,part B consist of source of information ,part C consist of 11 close ended questions with multiple options, which were framed to enquire respondents of:

1. Knowledge about physiotherapeutic interventions

2. Physiotherapy as a course,services and availability

3. Physiotherapy intervention for various diseased condition

The questionnaire was distributed in one government and two private colleges of eastern Odisha. Responses were recorded inform of graph and bar diagrams. Participants were explained in detail regarding the purpose of the study; informed consent was obtained and questionnaires were distributed. Necessary steps were taken to maintain anonymity. 


\section{Results:-}

Statistics :-

Thousand students were given the survey questionnaire out of which only number of students who responded back to the questionnaire were only 607 out of which females were more than males. The following are the results of the survey:

\section{Source of information about physiotherapy:-}

According to the results of the survey the commonest source of information is found to be news paper/magazine (23.3\%), internet (23.3\%), visits to physiotherapy school/ hospital/etc (17.4\%), through advertisements(16.6\%), and less common sources of information are televisions (12.7\%), patient as client (12.6\%), films(10.8\%), friend as a therapist $(10.1 \%)$, teacher/counselor/coach $(10.1 \%)$, family physician $(9.4 \%)$, family member therapist $(7.8 \%)$, volunteer $(6.6 \%)$, career day/health care $(5.6 \%)$, radio $(5.5 \%)$, personally a client $(4.6 \%)$, friend is a client $(4.5 \%)$, literature $(2.5 \%)$, and people who are unaware of physiotherapy from any of the above mentioned sources $(40.7 \%)$.

\section{Awareness in physiotherapy:-}

In the survey done about the awareness of physiotherapy it is very abashing to recognize that many of the students are unaware of physiotherapy its treatment methods, infrastructure it contains and their usage, role of physiotherapy in diseased conditions other than sporting activities. Out $100 \%$ the response percentages were very unsatisfactory.

\section{The percentage responses for each question is given below:-}

1. Q.no1:-23\% of students attempted the correct answer while 33\% of them did not attempt the question and $44 \%$ attempted multiple or other individual options.

2. Q. no2: $6 \%$ of students attempted the right answer, $35 \%$ did not attempt and the remaining $10 \%$ of students marked multiple options.

3. Q. no3: $14 \%$ of students attempted all four options which is correct option and 33\% did not attempt the question whereas $28 \%$ marked single options and $25 \%$ students marked other mixed options.

4. Q. no4: $25 \%$ of student's marked right option, $34 \%$ did not attempt and $16 \%$ marked all four options and other $25 \%$ attempted one or multiple options.

5. Q. no5: only 7\% marked correct answer, $37 \%$ did not attempt the question $37 \%$ marked any one of the option and other $20 \%$ marked multiple options.

6. Q. no6: $9 \%$ attempted right option 37\% didn't attempt whereas 34\% marked individual options and $20 \%$ marked multiple options.

7. Q. no7: $11 \%$ of students marked correct option, $37 \%$ did not attempt $31 \%$ marked individual options and other $21 \%$ marked multiple options.

8. Q. no8: $6 \%$ of them attempted all four options which is correct,31\% marked any of the single option, $20 \%$ marked other multiple options where as $43 \%$ did not mark any of the options.

9. Q. no9: only 5\% of the students attempted all options which is right and majority i.e. is $47 \%$ did not answer, $34 \%$ answered individual option and the other $10 \%$ attempted other multiple answers.

10. Q.no10: 7\% of them marked the correct options, $42 \%$ did not mark any of the options, $32 \%$ attempted individual options and $19 \%$ marked other multiple options.

11. Q.no11: $10 \%$ of the students marked all four options which is right, $38 \%$ not attempted the question, $33 \%$ marked only any one of the options and $19 \%$ attempted other multiple potions.

Tables and graphs:-

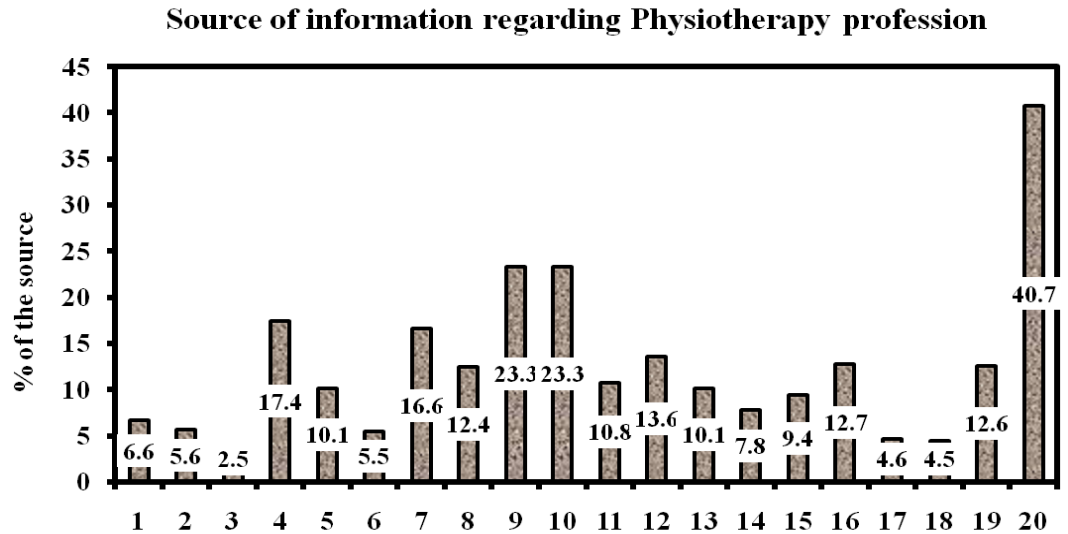


Percentage distribution of Answer for Question No.1

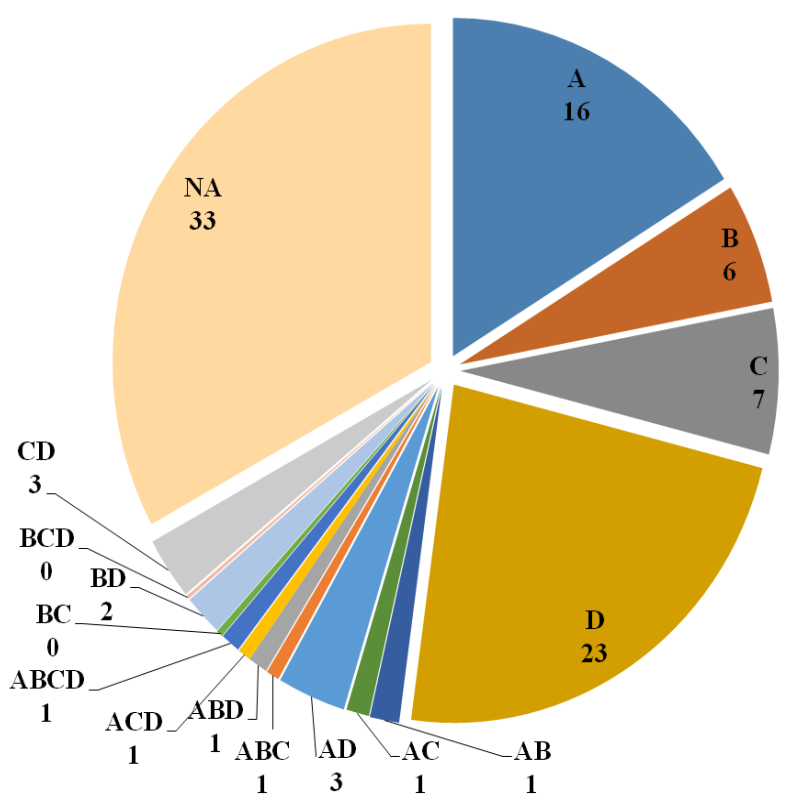

Percentage distribution of Answer for Question No.3

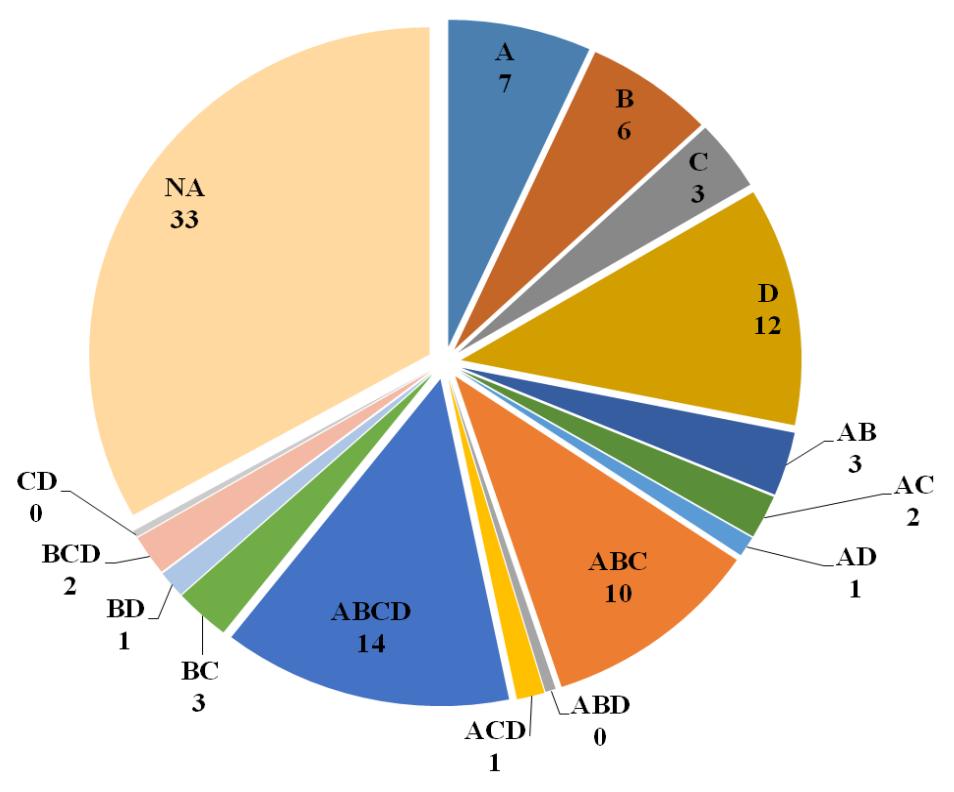

Percentage distribution of Answer for Question No.2

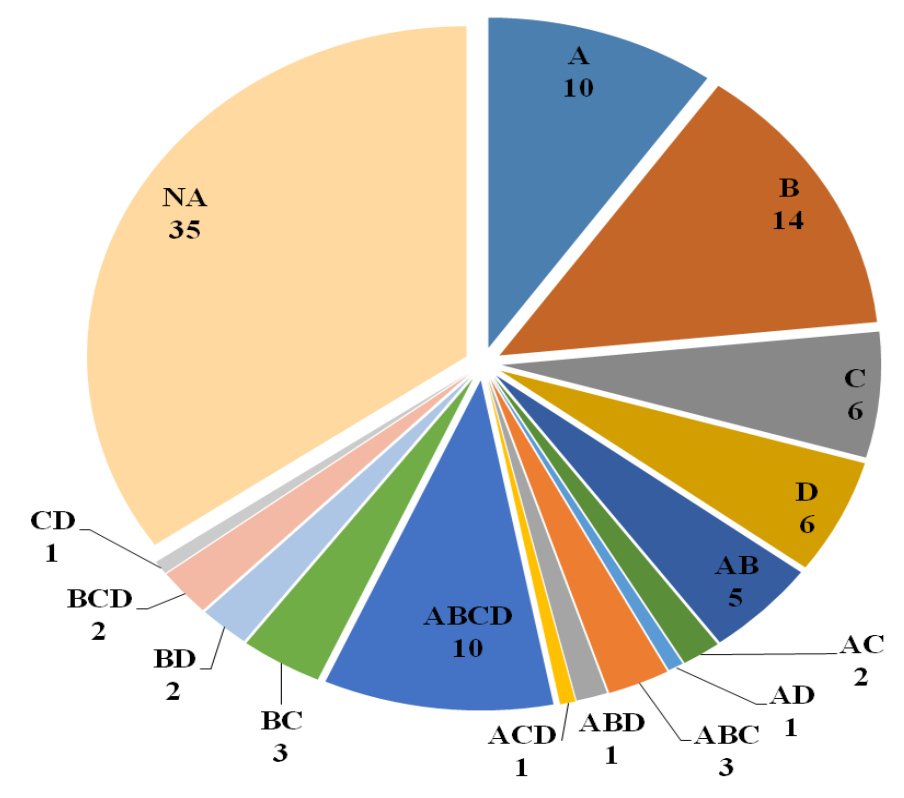

Percentage distribution of Answer for Question No.4

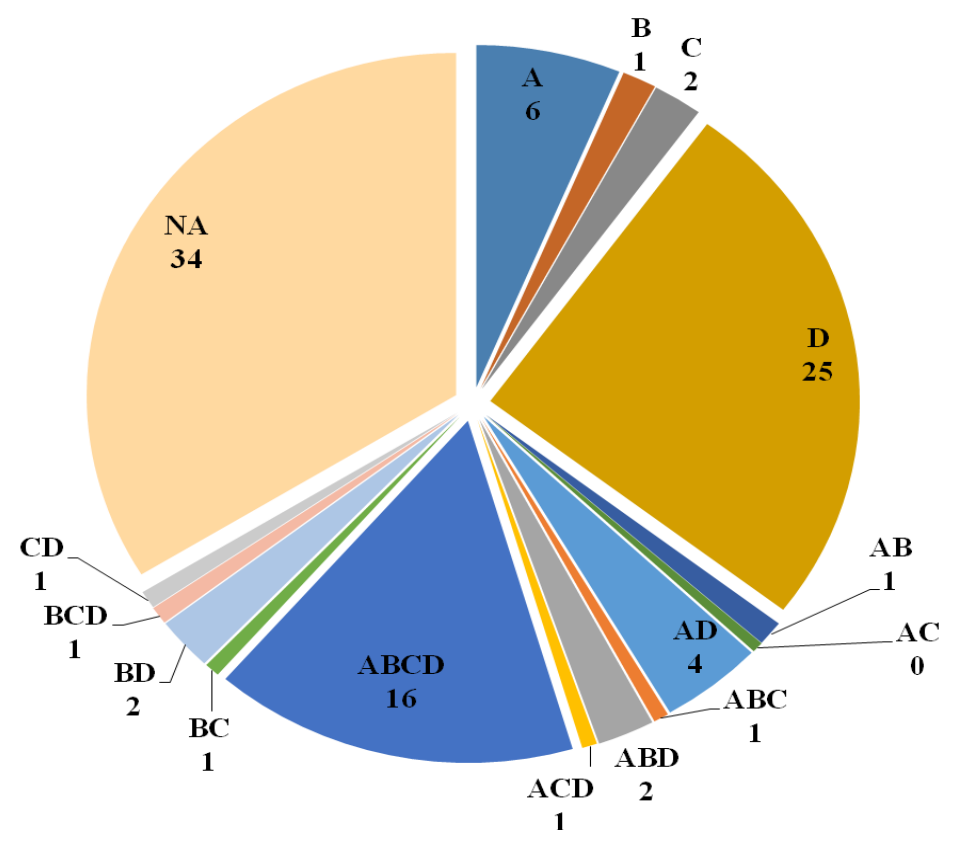


Percentage distribution of Answer for Question No.5

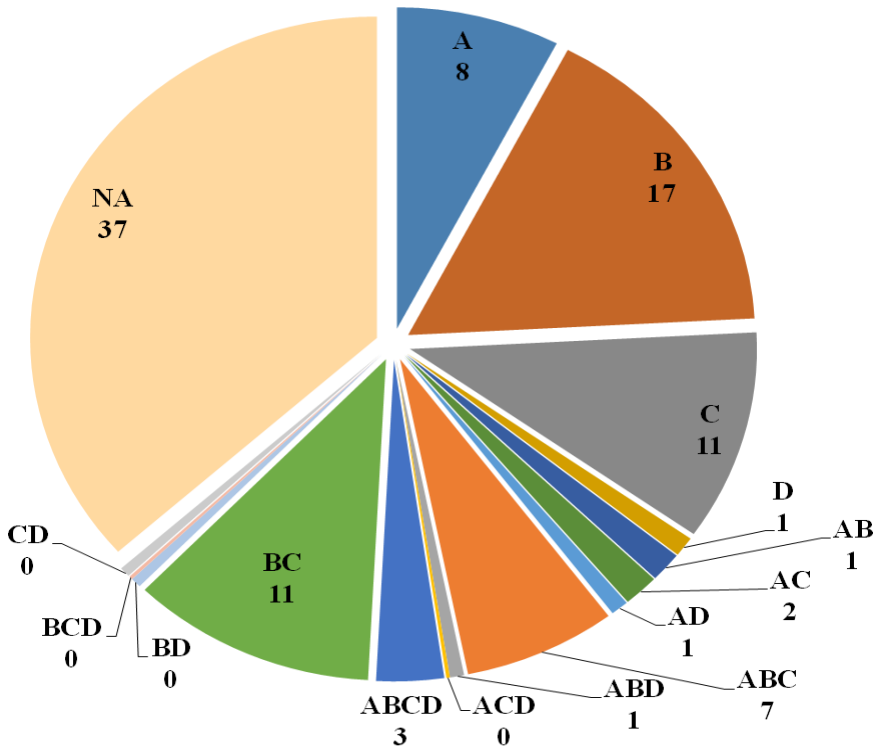

Percentage distribution of Answer for Question No.7

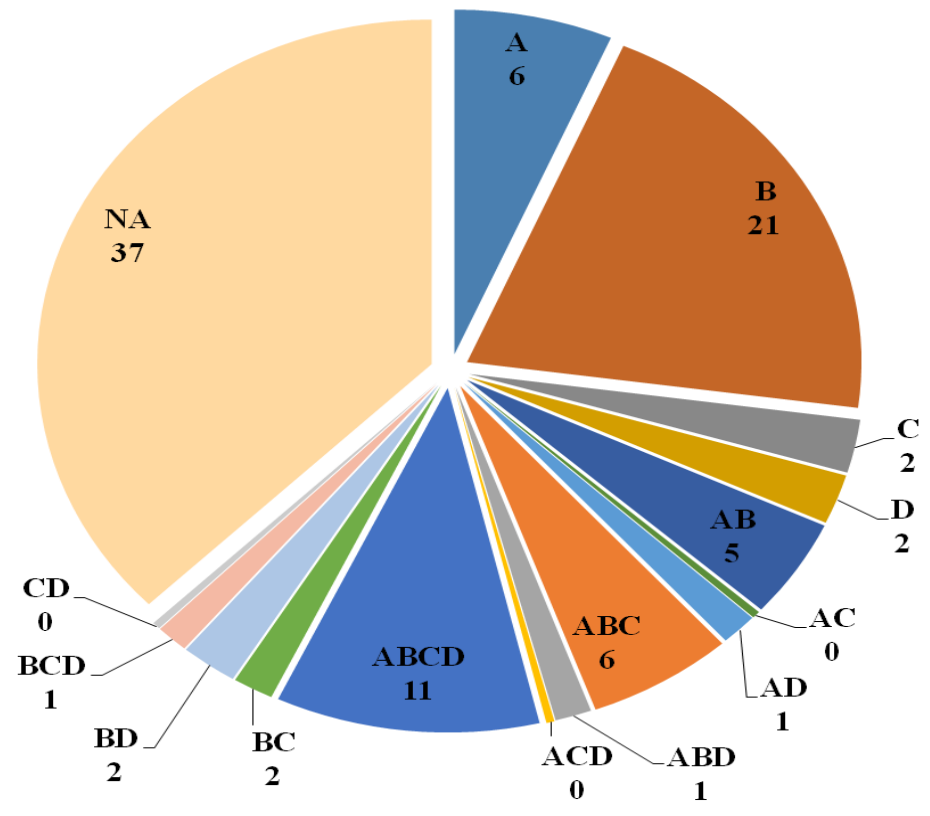

Percentage distribution of Answer for Question No.6

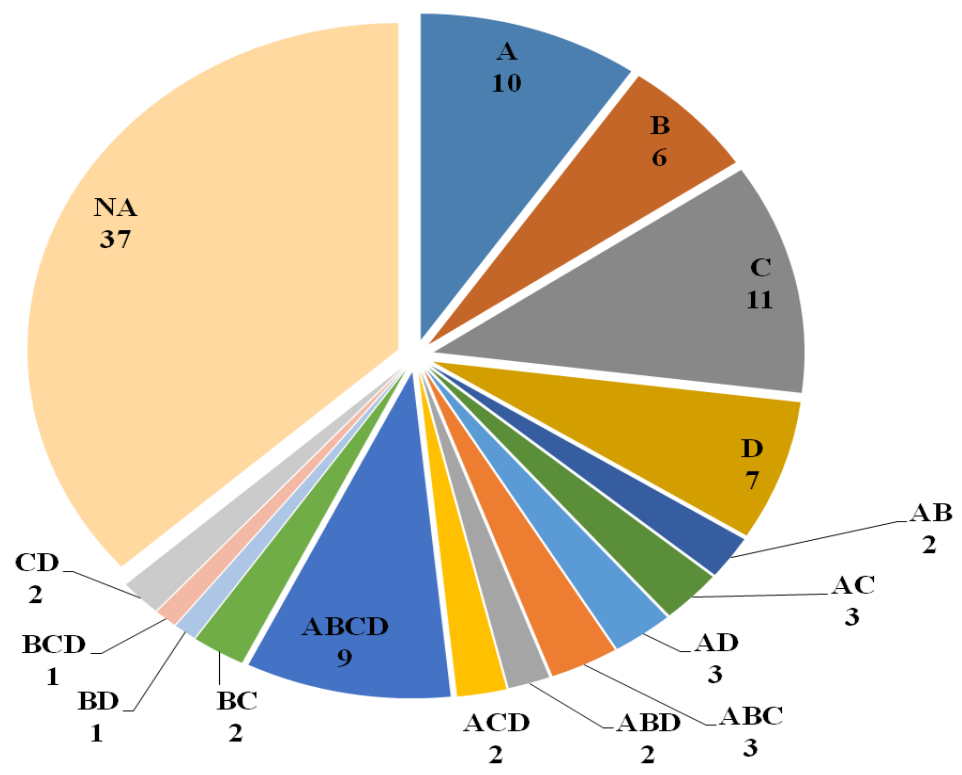

Percentage distribution of Answer for Question No.8

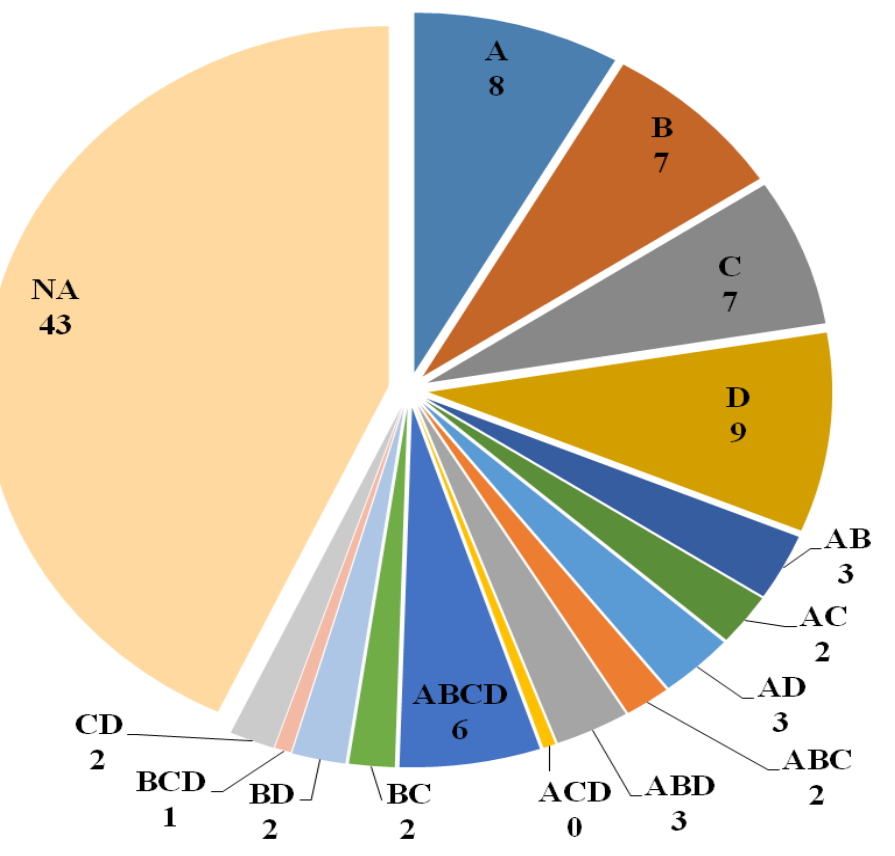


Percentage distribution of Answer for Question No.9

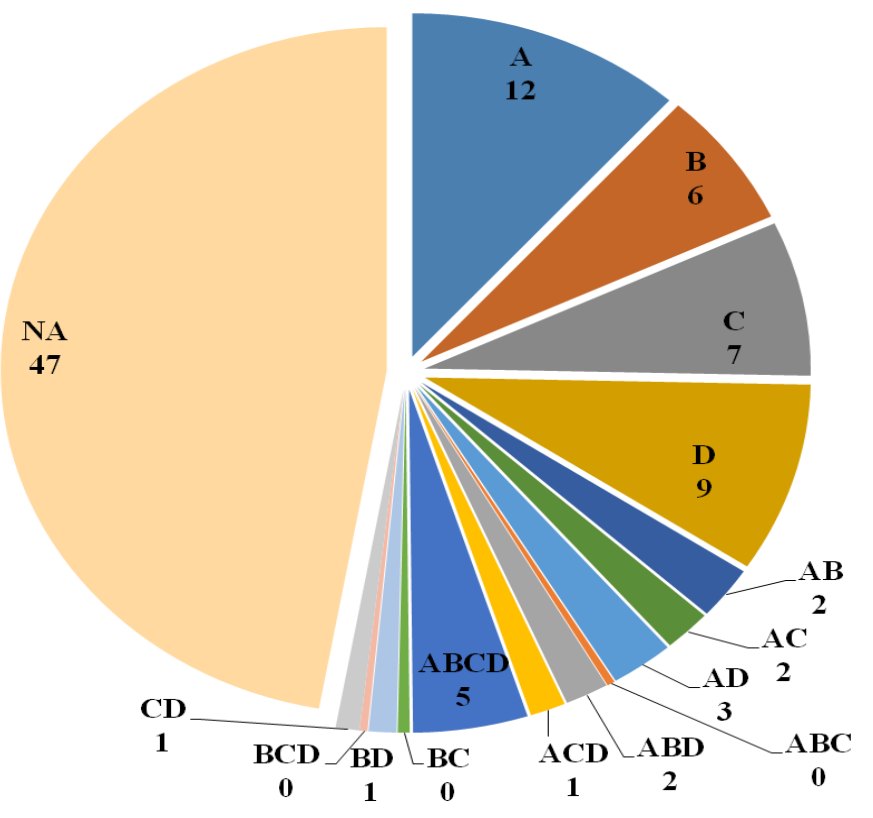

Percentage distribution of Answer for Question No.10

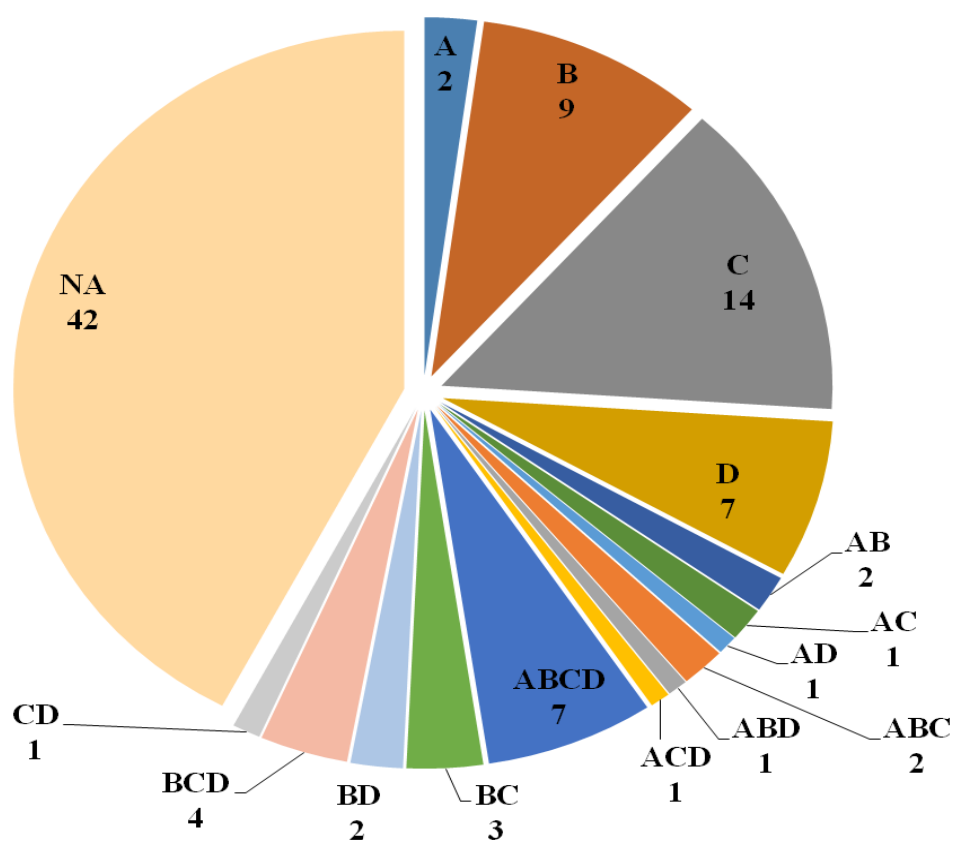

Percentage distribution of Answer for Question No.11

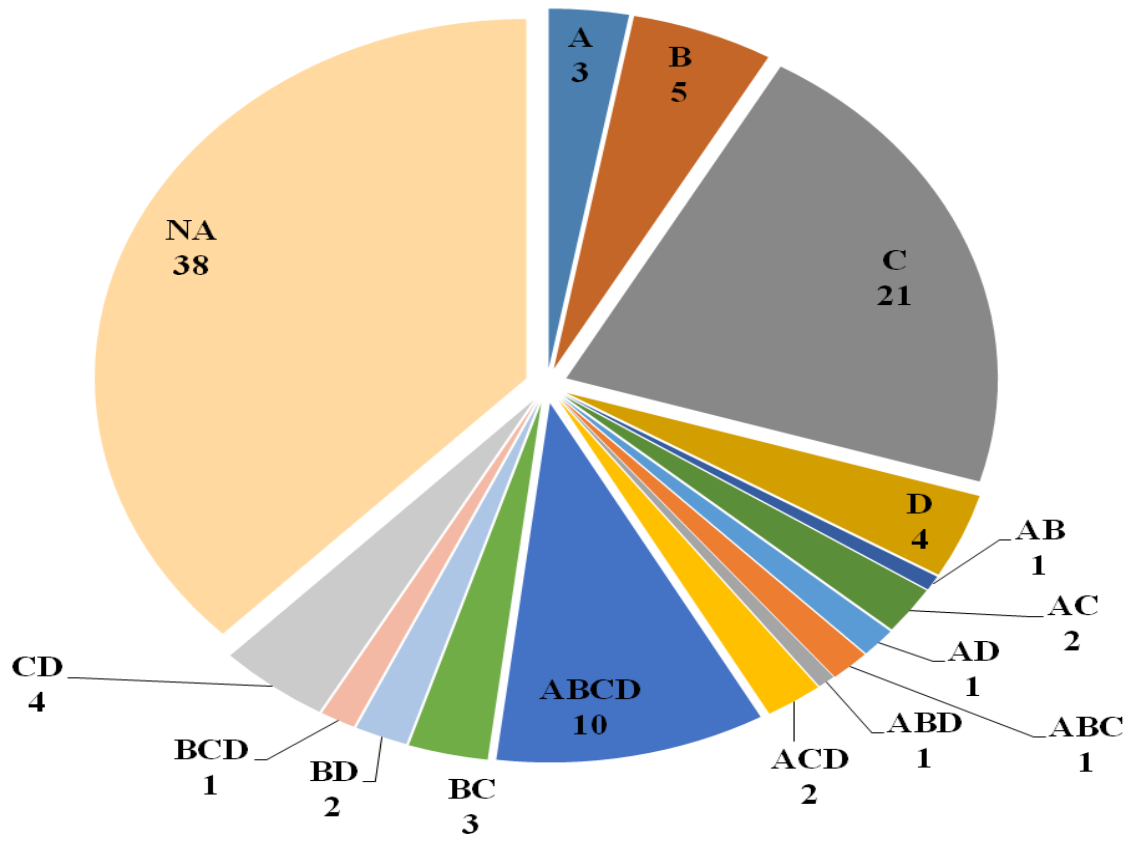




\section{Discussion:-}

This study was conducted to get an idea on the fact whether high school students are aware about physiotherapy as a course to pursue and what are its utility as an entity in health care field. The selected population is higher secondary with science background .In Odisha, under Utkal university the basic prerequisite for a student to enroll under physiotherapy course is its specificity of physics, chemistry and biology as subjects in higher secondary. The basic awareness about Physiotherapy among higher secondary students is not satisfactory, they only had a knowledge of it only as an adjunct in case of sports injuries. The commonest source about was through news paper ,internet and movies of recent kind.Abd RazakZakara etal implicated the existing higher secondary curriculum in Malaysia should be revised by introducing Physiotherapy. Riju etal emphasized that there is a need for a programme for school children in Anand city of India to educate them about Physiotherapy. According to Ginzberg (1972) theory, between early to late adolescent is the period in which career choice is made. According to Super's developmental theory, individuals between the ages 15 and 24 years are at the exploration stage of their development. This phase is characterized by the making of tentative choices and skill development. In India the students will be in higher secondary level at the age of 16-18 and that is the period to select their future career. Hence we have to provide adequate information about the profession through print and electronic media so that the student may take Physiotherapy as career in health care.

Many of them believe Physiotherapy is practiced by doctors, it indirectly depicts Majority of the students are not aware physiotherapy is a unique profession and practiced by Physiotherapist. It is also noticed that student assumes masseurs are Physiotherapist, But the fact is Physiotherapist practice massage as a part of their therapeutic maneuver where and when required depending on the condition. When we compare with similar studies done by Shimpachiro etal in japan among ishikawa high school students it was noted $58 \%$ of respondents were believed to have had some knowledge in Physiotherapy. Whereas in the study conducted in high school students in Sri Lanka more than $63 \%$ of them were unaware about physiotherapy profession \& its applications in patient management. Hence similar trend is noticed among the students in Japan and in Sri Lanka. The awareness seems to be coherent to the similar study conducted at Meerut etal (India) in which $41 \%$ of higher secondary students had an idea about Physiotherapy .In contradict to the first finding (awareness about physiotherapy), it was inferred satisfactorily about the role of physiotherapy in the improvement of fitness level of sportsperson. This is an interesting finding that majority of the sample where mot much aware of the role of physiotherapy in rehabilitation of injuries, improving quality of life of injured person, regaining activities of daily living. The awareness about other modalities other than electrical modality is not satisfactory. Many students believe physiotherapist uses electrical modality more than manual techniques, exercise equipment. Similar result but a very high awareness about electrical modality (95\%) is noticed in the similar study conducted in srilanka. In difference to the above finding many students aware about manual therapy $(82.22 \%)$ followed by electro therapy and exercise therapy $(75.56 \%)$ as a mode of Physiotherapy treatment. The awareness about ice/heat therapy and hydrotherapy is not satisfactory. This is highly controversial to the previous finding Many students believe Physiotherapy unit comprises of electrical modalities (40\%) followed by therapeutic pool $(40 \%)$. This results shows the students are not very clear about the mode of Physiotherapy treatment and component of Physiotherapy unit. Only few are aware of all four (Manual therapy, Ice/heat therapy, hydrotherapy, electrotherapy \& exercise therapy) components of Physiotherapy. Though only less than half of the samples aware that Physiotherapy can improve the fitness level of sports person, there is a good awareness about when to meet the team Physiotherapist. It is evident from the study most of the respondents aware of Physiotherapy is useful in Musculoskeletal and neurological conditions only. The similar findings noticed in the study conducted by Riju etal among high school students in Anand district (India). Kacie etal who conducted a study among public at Kansas city, United states the highest awareness of Physiotherapy is musculoskeletal conditions (90\%).This study implicates the awareness about the role of Physiotherapy in other specialty ( Cardiorespiratory, Women's health, Paediatrics) needs improvisation and random awareness camp for the same .

\section{Conclusion:-}

The students have a moderate awareness about Physiotherapy, The awareness about the role of Physiotherapy in specialties other than orthopaedics and neurology is not satisfactory, Television has been identified as the major source of information about the Physiotherapy. 


\section{Further Recommendation:-}

Measures has to be taken to increase the awareness among the students. A brief introductory session can be conducted to higher secondary students to develop better awareness about the profession which would enlighten the minds of aspiring students to choose Physiotherapy .

\section{Acknowledgement:-}

I would like to pay my hearty gratitude and benevolence to the Almighty, who showered his blessings to make my paper a successful one and my parents for their support throughout.

\section{References:-}

1. Greenwood N, Bithell C. Perception of physiotherapy compared with nurcing and medicine amongst minority ethnic and white UK students: Implications for recruitment. Physiotherapy. 2005; 91

2. Dastoor, D. Looking back at 50 years of Physiotherapy. Physiotherapy Publication of school \& centre of Physiotherapy, Seth GSMC \& KEMH. 2003.

3. Shimpachiro Ogiwara, Masafumi Nozoe. Knowledge of Physiotherapy: A Study of Ishikawa High School Students.J.Phys.Ther.Sci, 2005;17(1):9-16.

4. Thusharika D. Dissanayaka, Shayama Banneheka. Awareness in Physiotherapy among High School Students.International Journal of Scientific and Research Publications 2014;4(7):4.

5. Agarwal Yashaswi, Agarwal Manish, Gupta Nalina. Awareness of Physiotherapy among Higher Secondary Students and Perseverance among Physiotherapy Students and Professionals in Meerut - A survey,Indian Journal of Physiotherapy \& Occupational Therapy 2012;6(1):176.

6. Thusharika D. Dissanayaka, Shayama Banneheka. Awareness in Physiotherapy among High School Students.International Journal of Scientific and Research Publications 2014;4(7):4.

7. Riju D.Patel. Awareness about Physiotherapy Among High School Students of Anand District.International Journal for Innovative Research in Multidisciplinary field 2015;1(1):4.

8. Kacie Rognlie, Yvonne Searls (2011).Public perception of Physical therapist scope of practice. Journal of student Physical Therapy Research 2011;4(2):10-17.

9. Zakaria, Abd.Razak, Hazleena Baharun and Zuwati Hasim (2014). Prospect of Physiotherapy Profession and requirements for changes in High School Curriculum. 2014;1(2):65-70.

10. Osakinle E.O. In-School Adolescents and Career Choice: The Case Of Ekiti State, Nigeria. Journal of College Teaching \& Learning. 2010;7(9):43.

11. Roopchand Martin S and Noel G. Secondary School students Knowledge of Physical Therapy. West Indian Med J. 2014;63(2):151-158.

12. Wilson D. (2005-2011), Physiotherapy; What is Physiotherapy?,bodyworks Physiotherapy clinic, Available from http://www.bodyworksphysio.com/html

13. Mosby's Medical Nursing and Allied Health Dictionary. (2006), 7th edition, Mosby: St Louis.

14. Sri Lanka's aging population present risks, opportunities, Available from http://www.lankabusinessonline.com/.../sri-lankas-agingpopulation.com/html

15. Gotlib J, Bialoszewski D, Opavsky J, Garrod R, Fuertes NE, Gallardo LP, Loourido BP, Monterde S, Serrano CS, Sacco M, Kunicka I. Attitudes of European physiotherapy students towards their chosen career in the context of different educational systems and legal regulations pertaining to thepractice of physiotherapy: Implication for university curricula. Physiotherapy. 2011.

16. Ogiwara S, Nozoe M. Knowledge of physiotherapy: a study of Ishikawa High School students. Journal of Physical Therapy Science. 2005; 17: 9-16.

17. Gotlib J, Bialoszewski D, Sierdinski J, Jarosz MJ, Majcher P, Borczyk K, Bauer A, Anna C, Grzegorczyk J, Piaszewski M, Kulak W, Czupryna O, Prokopowicz K. A comparison of the perception and aspirations of third year physiotherapy students trained in three educational settings in Poland. Physiotherapy 2010; 96(1): 30-32.

18. Jayawardana RADWU, Fernando DAT, Priyadarshani WDMD, Lakmali NPN, Jeewani PKGT, Kumari WAKD, Nadaraja T, Amunugama ARMSS, Rajarathne AAJR, Liyanage E, Pallegama RW. (2011). Evaluation of Awareness about Physiotherapy and Identification of the Most Vulnerable Region to Injury among School Level Male Hockey Players in Kandy Educational Zone. Proceedings of the Peradeniya University Research Sessions, Sri Lanka. 2011;16: 58.

19. Minimum Z-Score for academic year 2012/2013, Available from http://www.ugc.ac.lk.com/html

20. Medico-Economic research Organization: The 1996 White Paper on Health Care, Tokoyo: Nihon IryoKikaku, 1966, pp 351-352. 